\title{
RESULTS OF THE INTERNAL AUDIT IN THE ENVIRONMENTAL MANAGEMENT SYSTEM OF THE BRAZILIAN ANTARCTIC SCIENTIFIC STATION "COMANDANTE FERRAZ"
}

http://dx.doi.org/10.4322/apa.2014.086

\section{Alexandre de Avila Leripio ${ }^{1, *}$, Bruna Barni Pereira², Gustavo Rohden Echelmeier ${ }^{2}$, Leda Pavani²}

\author{
${ }^{1}$ Programa de Mestrado em Gestão de Políticas Públicas, Universidade do Vale do Itajaí - UNIVALI, \\ Rua Uruguai, 458, Sala 401, Bloco 16, CEP 88302-202, Itajaí, SC, Brazil \\ ${ }^{2}$ Centro de Ciências Tecnológicas da Terra e do Mar, Universidade do Vale do Itajaí - UNIVALI,
} Rua Uruguai, 458, Sala 10, Bloco 26, CEP 88302-202, Itajaí, SC, Brazil

*e-mail: leripio@terra.com.br

\begin{abstract}
With the purpose of strengthening and formalizing the fulfilment of the principles relating to the Antarctic environment protection established in the Madrid Protocol, an Environmental Management System certifiable to ISO14001:2004 was set up at the Brazilian Antarctic Scientific Station "Comandante Ferraz" (EACF, from now on), to limit the negative environmental impacts. The internal audit of the Environmental Management System of EACF was conducted between December 2011 and January 2012, to verify the compliance of facilities and activities of the EACF in relation to the requirements established by the standard, aiming at the certification audit, scheduled for November 2012.The audit was conducted through interviews, data collection, observations and analysis of documents and records, and then the findings were discussed and the non-conformities identified. The level of compliance of the EACF with reference to the requirements of the standard ISO 14.001:2004 came to 86,2\%. The conclusion arising from the findings is that the organization is in a situation of partial compliance with the requirement staken as a reference and scope of the environmental audit.
\end{abstract}

Keywords: Environmental Management System, Antarctica, Comandante Ferraz, ISO 14.001:2004

\section{Introduction}

The concern with the quality of the environment is not new, but it was in the late twentieth century that it was finally inserted in the plans of the governments of many countries and different segments of society such as among economists, scientists and as part of technological concerns.

In this same period, there was an advance in terms of institutionalizing a new political world aimed at environmental responsibility and sustainable development, result of a more critical analysis of the relationship between society and the environment that goes beyond geographical and temporal boundaries.

The organizational responsibility of the environment stopped being only a mandatory feature to become a voluntary action, exceeding the expectations of society.
Antarctica is the continent whose natural conditions are most preserved, where environmental impacts can cause irreversible consequences and, for this reason, it is appropriate to be above the legal requirements. Given this, the Environmental Management System (EMS from now on) goes beyond being just a preventive strategy to constitute a need in itself, this because, environmental quality requires at least a more rational use of inputs, an aspect of great importance when we speak of supply logistics for Antarctic stations.

In order that the commitments made by Brazil for the international community are met with an emphasis on preventive attitudes, during the years 2010 and 2011 the certifiable EMS ISO 14001:2004 was set up at EACF, which 
had the objective of strengthening and formalizing the fulfillment of the principles relating to protection of the Antarctic environment established in the Madrid Protocol, to limit the negative environmental impacts in the Antarctic environment.

Indispensable to the EMS, the internal audit was conducted between December 2011 and January 2012 with the objective of verifying the compliance of EACF installations and activities with requirements established by ISO 14001:2004 aiming at the certification audit, which was scheduled for November 2012.

It was observed with the internal audit that the organization is in a situation of partial conformity with the requirement staken as a reference and the scope of the environmental audit, reaching $86.2 \%$ of compliance with the requirements of ISO14001:2004.

It is noteworthy that, the EMS of EACF will not obtain a certification audit pass, because on February 25th, after the internal audit, a serious accident occurred with the outbreak of fire at EACF, destroying it completely and causing the deaths of two Brazilian military.

\section{Materials and Methods}

The internal environmental audit was carried out to verify the compliance of EACF installations and activities, in relation to the requirements of ISO 2004, which provides for Environmental Management System - Specification with Guidance for Use (ISO 14001, 2004).

The internal audit process was applied in all EACF installations and activities that were covered by the EMS.

The focus of the internal audit concerned the processes that have activities with aspect and impact significance and so have specific procedures developed in the EMS of EACF.

The steps of the audit were conducted in modules that had activities contemplated in the EMS of EACF. Firstly the objective and scope of the audit was defined, and then the documents requested for preliminary analysis.

After the preliminary analysis of the documents, the preparation stage for the audit was initiated, which defined the Audit Plan, for this, the audit team was selected and trained, and finally the work documentation, the check-list and audit protocols were developed.
The checklist was developed and used to facilitate and ensure that the observations and search of non-compliances were conducted on all the EACF modules contemplating all the procedures established in the EMS documentation.

The audit team consisted of the group-base of Brazilian Navy and researchers from the National Institute of Environmental Science and Technology of Antarctic Environmental Research (INCT-APA).

With the documents and team ready, the audit was initiated, first undertaking the opening meeting, which presented the objective and scope, the audit team, the timing of the audit and the guides who accompanied the audit by the audited.

The audit was conducted through interviews, data collection, observations and analysis of documents and records, and then the findings were discussed and the nonconformities defined.

The audit report was presented to the management representative, to show the collected data and the conclusions of the audit, and so, confirm the proposed plans of action or suggest other strategies for the correction of non-conformities.

\section{Results}

The completion of the internal audit counted with the full support of everyone in the EACF, especially the members of Brazilian Navy, sometimes acting like internal auditors or like support team to achieve this important stage of EMS of the EACF.

With the realization of the Environmental Audit inside the installations and processes of the organization, some evidence that formed the basis for findings was collected, which indicates the need for corrective and preventive actions in order to fully attend the established recommendations set by default reference adopted.

As a summary of the findings we have made the identification of five non-conformities of great importance, non-conformity with less significance and ten observations.

The conclusion resulting from the findings is that the organization is in a situation of Partial Compliance with the requirements taken as a reference and scope of the environmental audit. 
REQUIREMENTS OF ISO 14.001:2004

Attendance Level

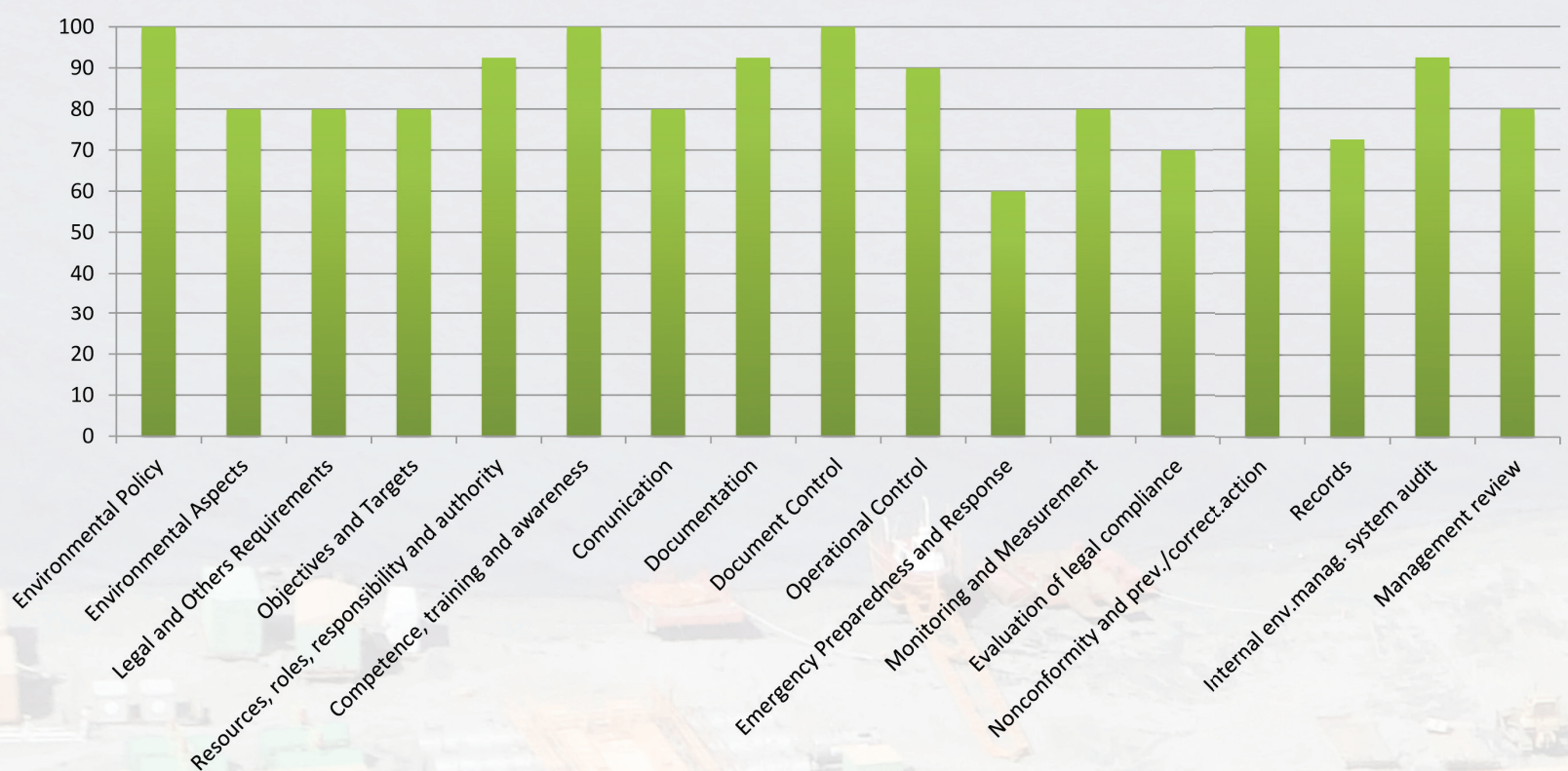

Figure 1. Requirements of ISO 14.001:2004

Grouping the results obtained for each requirement of ISO 14.001:2004 in applying the evaluation tool allowed the results shown in Figure 1.

Overall, the level of attendance of EACF in reference to the requirements of the ISO 14.001:2004 was $86.2 \%$, where the principle "Environmental Policy" was the only one which achieved $100 \%$ of compliance.

\section{Discussion}

By reason of non-registration of new activities with potential impact on the environment and no clear definition of the plan presented at the Expedition XXIX about the objectives, the principle of "planning" which involves items Environmental Aspects, Legal Requirements and Objectives, Targets and Programs reached a level of $80 \%$ compliance.

The highest level of compliance was observed in the requirements referred to "Implementation and Operation" at $88 \%$ : Resources, roles, responsibilities and authorities (93\%), Competence, training and awareness (100\%), Communication (80\%), Documentation (92\%), Control of Documents (100\%), Operational Control (90\%) and
Emergency Preparedness and Response, however, the latter was the item with the lowest attendance requirements (60\%), special attention should be given to the implementation of corrective actions related to it.

The group of items "Monitor and Measure" reached a level of compliance with the requirements of $83 \%$, requiring corrective actions, in relation to registration and updating procedures adopted in EACF.

Finally, the principle of "Review and Improvement" scored the second lowest compliance with the requirements of the standard, $80 \%$, due to the administrative disputes involving EMS of EACF.

\section{Conclusions}

Some observations have resulted in adapting the EMS documents of EACF when the way the activity was performed was more appropriate or more applicable to the reality of the Antarctic environment, otherwise, when non-conformities were identified, the best way to solve them was sought through discussions with stakeholders in the 
area, or by bibliographic research, resulting in the proposed recommendations for each finding.

Special attention on the part of the organization with respect to major non-conformities mentioned in the report was recommended, noting that the internal audit function is to check the pending items and record them properly, being the Chief of EACF, as management representative, the responsible for reporting and performing periodic requests for PROANTAR (Brazilian Antarctic Program) based also on the internal audit report, with the support of the coordinator of internal audit, Sub-Chief of EACF.

\section{Acknowledgements}

This work integrates the National Institute of Science and Technology Antarctic Environmental Research (INCTAPA) that receives scientific and financial support from the National Council for Research and Development (CNPq process: $n^{\circ}$ 574018/2008-5) and Carlos Chagas Research Support Foundation of the State of Rio de Janeiro (FAPERJ $n^{\circ}$ E-16/170.023/2008). The authors also acknowledge the support of the Brazilian Ministries of Science, Technology and Innovation (MCTI), of Environment (MMA) and InterMinistry Commission for Sea Resources (CIRM).

\section{References}

International Organization for Standardization - ISO. (2004). NBR ISO 14.001:04: Environmental Systems Management Specifications and Directives of Usage. Rio de Janeiro: ABNT. 